\title{
Ectopic prolactin secretion secondary to an ovarian tumour
}

\author{
Sowmya Gururaj, K Nisal, Q Davies, S Deen ${ }^{1}$ and P G McNally
}

Correspondence

University Hospitals of Leicester, Leicester, UK

to S Gururaj

${ }^{1}$ Nottingham University Hospital, Nottingham, UK

Email

doktrsowmya@gmail.com

\section{Summary}

Ectopic hormone secretion is a well-recognised phenomenon; however, ectopic prolactin secretion is exceptionally rare. Hoffman and colleagues reported the first ever well-documented case of ectopic prolactin secretion secondary to a gonadoblastoma. We report a lady who presented with galactorrhoea and a large ovarian tumour that was found to secrete high levels of prolactin.

\section{Learning points:}

- Aim of this case report is to highlight the occurrence of this condition.

- Lack of awareness can often lead to a diagnostic conundrum.

\section{Background}

We report this case to make clinicians aware of this rare condition (1) (2). Hoffman and colleagues reported the first ever well-documented case of ectopic prolactin secretion secondary to a gonadoblastoma (1).

\section{Case presentation}

A 27-year-old lady presented with 8-week history of hot flushes, headaches, galactorrhoea and delayed periods. She denied any problems with vision or fluctuation in weight. Her medical history was asthma and irritable bowel disease. She was an ex-smoker of 5 years with a two packs per year smoking history and drank alcohol occasionally. On examination, she was noted to have galactorrhoea on expression. She had normal visual fields tested by confrontation method. Systemic examination revealed a $10 \mathrm{~cm}$ supra-pubic mass on palpation.

\section{Investigations}

\section{Biochemistry}

Her initial prolactin level returned at $24642 \mathrm{mIU} / 1$ (normal range 50-400 mIU/l) with suppressed $\mathrm{LH}$
$<0.5 \mathrm{IU} / 1, \quad$ FSH $2.7 \mathrm{IU} / 1$ and $17 \beta$-oestradiol $\left(\mathrm{E}_{2}\right)$ $83 \mathrm{pmol} / \mathrm{l}$. She had normal TSH $1.8 \mathrm{mIU} / 1$ (0.30-5.00), thyroxine $12 \mathrm{pmol} / \mathrm{l}(9-25 \mathrm{pmol} / \mathrm{l})$ and normal cortisol response to short synacthen test (basal 251- and 30-min levels of $753 \mathrm{nmol} / \mathrm{l})$. Her tumour markers showed CA 125 antigen $67 \mathrm{kU} / \mathrm{l}(0-35)$, alphafetoprotein $83 \mathrm{kU} / \mathrm{l}$ (0-10), CA19-9 antigen $19 \mathrm{kU} / \mathrm{l}(0-10)$ and carcinoembryonic antigen $<2(0-5)$. Her repeat prolactin level was $36066 \mathrm{mIU} / \mathrm{l}$.

\section{Imaging}

Magnetic resonance imaging of the pituitary was normal. Her computed tomography (CT) of the abdomen showed a right adnexal mass measuring $18 \times 14 \times 18 \mathrm{~cm}$ with retroperitoneal lymphadenopathy (Fig. 1).

\section{Treatment}

Therapy with cabergoline was initiated but discontinued due to intolerance. She was then started on bromocriptine $2.5 \mathrm{mg}$. She underwent right salpingo-oophorectomy with para-aortic node clearance. Three weeks postoperatively, her prolactin dropped to undetectable levels.

$\begin{array}{rr}\text { (C) } 2013 \text { The authors } & \text { http://www.edmcasereports.com } \\ \text { Published by Bioscientifica Ltd }\end{array}$




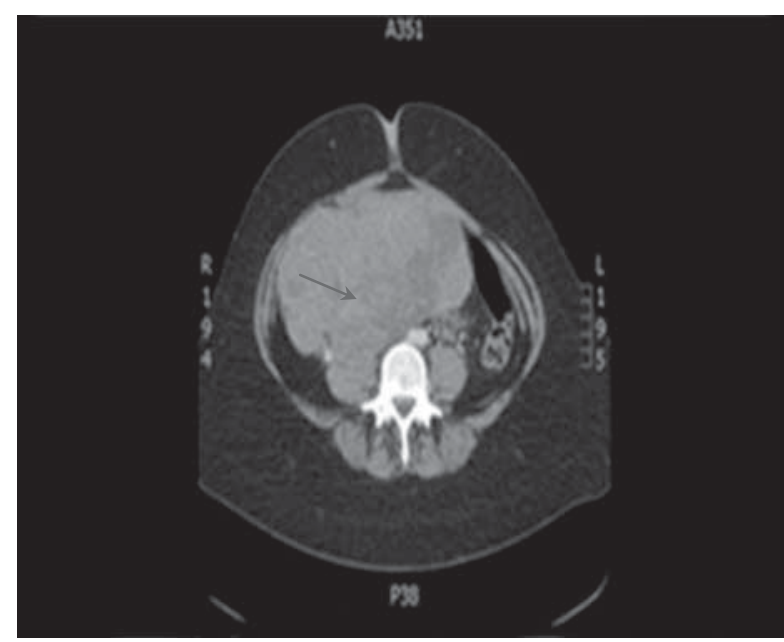

Figure 1

CT abdomen showing large right adnexal mass (red arrow).

Bromocriptine was discontinued. Her prolactin levels remained normal (Fig. 2) at 367 and $81 \mathrm{mIU} / 1$ with a normal LH 2.2, FSH 2.8 and $\mathrm{E}_{2} 355 \mathrm{pmol} / \mathrm{l}$.

\section{Outcome and follow-up}

Post-operative histopathology, immunohistochemistry results under haematoxylin and eosin stain showed that the ovary was replaced by diffuse sheets of undifferentiated, highly atypical cells possessing enlarged nuclei. Tumour cells were positive for synaptophysin, p53 and epithelial membrane antigen (EMA), and showed negative expression for chromogranin, CK7, desmin, inhibin, melanA, PLAP and CD56. Following immunohistochemistry, the tumour was categorised as ovarian malignant

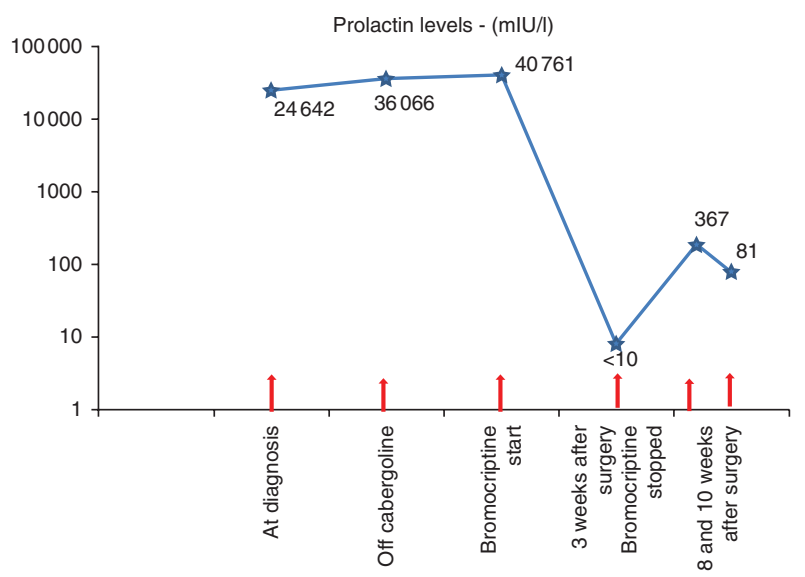

Figure 2

Prolactin levels (mIU/l)

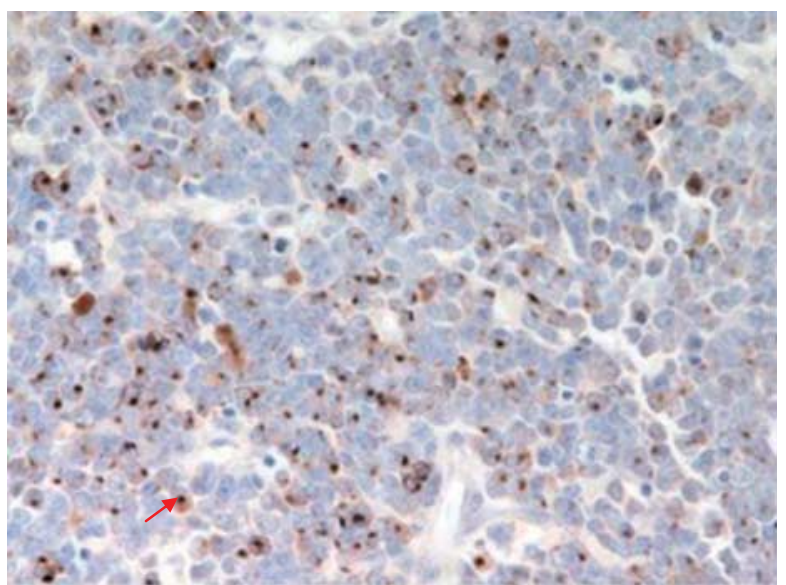

Figure 3

Prolactin immunoreactivity is evident in the cytoplasm, with peri-nuclear dot-like positivity of tumour cells (red arrow). Magnification $40 \times$.

small cell tumour of pulmonary type. Immunohistochemical staining for prolactin showed patchy but intense cytoplasmic, peri-nuclear dot-like positivity, which was reported to perhaps represent localisation of prolactin in Golgi complex (Fig. 3).

This patient had adjuvant chemotherapy following her surgery. Her PET FDG scan performed 10 weeks postoperatively showed right oophorectomy, unremarkable upper abdominal viscera, clear lung fields and no evidence of mediastinal, abdominal or pelvic adenopathy. She had no disease recurrence on her 8-month follow-up scan. Her prolactin levels remained normal.

\section{Discussion}

Our case demonstrates ectopic prolactin secretion secondary to an ovarian malignant small cell tumour. Normalisation of prolactin levels soon after surgical removal of the tumour, positive immunohistochemistry for prolactin and normal pituitary gland on imaging strongly support the diagnosis. We report this case to highlight and make clinicians aware of this rare condition.

Declaration of interest

The authors declare that there is no conflict of interest that could be perceived as prejudicing the impartiality of the research reported.

\section{Funding}

This research did not receive any specific grant from any funding agency in the public, commercial or not-for-profit sector. 
Patient consent

Written informed consent was obtained from the patient/patient's mother for publication of this case report.

\section{Author contribution statement}

Co-authors have contributed towards patient care, management and also towards writing and finalising the draft.

\section{References}

1 Hoffman WH, Gala RR, Kovacs K \& Subramanian MG 1987 Ectopic prolactin secretion from a gonadoblastoma, Augusta 30912-3770. Cancer 60 2690-2695. (doi:10.1002/1097-0142(19871201)60:11<2690::AIDCNCR2820601119>3.0.CO;2-J)

2 Kallenberg G, Pesce C, Norman B, Ratner R \& Silvergerg SG 1990 Ectopic hyperprolactinaemia resulting from an ovarian teratoma. Journal of the American Medical Association 263 2472-2474. (doi:10.1001/jama.1990. 03440180078036)

Received in final form 20 June 2013

Accepted 1 July 2013 